\title{
An Assessment of Quality of Life of Hypertensive Patients Visiting a Hospital in Warri, Nigeria
}

\author{
Rita 0 Akonoghrere ${ }^{1 *}$, Ogheneovo C Aghoja ${ }^{1}$, Omobamidele B \\ Betiku$^{2}$, Zipporah E Adje ${ }^{1}$ and Azuka C Oparah ${ }^{3}$ \\ ${ }^{1}$ Faculty of Pharmacy, Delta State University, Abraka, Nigeria \\ ${ }^{2}$ Department of Family Medicine, Lily Hospitals Limited, Warri, Delta State, Nigeria \\ ${ }^{3}$ Faculty of Pharmacy, University of Benin, Benin City, Nigeria \\ *Corresponding Author: Rita O Akonoghrere, Faculty of Pharmacy, Delta State \\ University, Abraka, Nigeria.
}

Received: June 02, 2020

Published: June 30, 2020

(C) All rights are reserved by Rita

0 Akonoghrere., et al.

\begin{abstract}
Purpose: Health related quality of life is a multi-dimensional concept that includes domains related to the physical, mental, emotional and social functioning. It appraises both the positive and negative aspect of life. This can be evaluated using various instruments so as to know areas to improve therapy. This study was done to assess the quality of life of a group of hypertensive patients, and to determine predictors of their quality of life.

Method: This was a descriptive cross- sectional study designed to assess the quality of life of hypertensive patients. The sf-12 questionnaire was used to assess Quality of Life in ambulatory patients. Data was obtained from patients visiting two facilities in Delta state, Nigeria.

Results: The total sample size used was 122 respondents of which 72 were males (58.5\%). The mean Physical Component Summary (PCS) of quality of life was $47 \pm 7.5$; while the mean Mental Component Summary (MCS) of quality of life was $46.7 \pm 9.2$. The mean systolic blood pressure was $139.6 \mathrm{mmHg} \pm 19.1$ while the mean diastolic blood pressure was $82.8 \mathrm{mmHg} \pm 13.3$. The Beta value obtained from all the analysis were $>0.05$, hence there were no significant predictors of quality of life.

Conclusion: Quality of life was generally low and below the Norm of 50\% according to the US standard. The physical component scale however was the most affected. Neither the clinical status nor the socio-demographics of the patients were predictors of their quality of life.
\end{abstract}

Keywords: Quality of Life; Blood Pressure; Hypertension; SF-12 Questionnaire; Nigeria

\section{Introduction}

Hypertension is seen to be a major cause of death and disability, and its prevalence is obviously increasing in developing and developed countries. It is considered to be the fourth most common cause of premature death in developed countries and the seventh in developing countries [1]. Therefore, assessing the quality of life of hypertensive patients is an important issue. This is dependent on blood pressure, organ damage, comorbidities and treatment.
Health-related Quality of life (HRQOL) is a multi-dimensional concept that includes domains related to the physical, mental, emotional and social functioning. It involves more than direct measures of health, life expectancy, including causes of death and focuses on the impact of the patient's health status on his quality of life. It appraises both the positive and negative aspect of life [2]. This can be evaluated using various instruments so as to know areas to improve therapy. 
Reasons for measuring HRQoL as presented by Higginson and Carr include: Identifying and prioritizing problems, facilitating communication, Screening for hidden problems, facilitating shared clinical decision-making, monitoring changes or responses to treatment [3]. A number of instruments can be used to measure quality of life, in this study however; the SF-12 questionnaire was used because it has been found to be reliable, cost effective and easy to complete.

Hypertension is an important worldwide public-health challenge because of its high prevalence and comorbidities. It has been identified as the leading risk factor for mortality and is ranked third as a cause of disability-adjusted life-years. The World Health Organization has concluded that hypertension is the major factor responsible for the most deaths worldwide $12.8 \%$ per year or more than seven million). More than a quarter of the world's adult population: nearly one billion (26\%) had hypertension in 2000 and was predicted to increase to 1.56 billion (29\% prevalence by 2025). However, these statistics vary from country to country [4]. Hypertension is the persistent elevation of arterial blood pressure (diastolic/or systolic) equal to or above $140 / 90 \mathrm{mmHg}$ (BP $\geq=$ $140 / 90 \mathrm{mmHg}$ ) in an adult of 18 years or above [5].

\section{Objective of the Study}

The primary objective of this study was to assess the quality of life of a group of hypertensive patients visiting an ambulatory clinic. The associations between quality of life and demographics variables in hypertensive patients were explored.

\section{Method}

Study design

This was a descriptive cross-sectional study.

\section{Research settings}

Two research settings were used for this study. This was done to reduce bias. The research was carried out at two hospitals in Delta State Nigeria. Delta State is in the southern part of Nigeria. The state is notable for its rich natural resource - crude oil, and therefore is a hub for most oil companies in Nigeria. The study was done in the city of Warri which is a commercial capital city of delta state with a population of over 311,970 people according to the national population census figures for 2006.

\section{Sample size determination}

A total of 122 patients were recruited for this study. These were ambulatory patients who visited the hospitals and gave their consent. The recruitment process spanned a month.

\section{Selection criteria}

Hypertensive patients above 18 years of age, with or without comorbidities, and who gave their consent to participate were included in the study. Newly diagnosed hypertensive patients, pregnant women and psychiatric patients were excluded.

\section{Research instrument}

The research instrument used in assessing Quality of Life (QoL) for this study was a standardized 12 item questionnaire - the United Kingdom SF-12v2 health survey (quality metric incorporated); standardized to fit a wide range of population. The questionnaire is divided into the Physical Component Summary (PCS) and the Mental Component Summary (MCS). The PCS measures 4 domains of health - physical functioning, role limitations due to physical health problems, pain, and general health; while the MCS measures another 4 domains of health - vitality, social functioning, emotional well-being and role emotional. A high score of above 50 in any of the components indicates good quality of life [6-8].

\section{Data collection method}

The SF-12 questionnaires were self-administered to all patients who gave their consent. Blood pressure reading were taken over a period of 3 consecutive visits to the hospital and the questionnaires were administered on the third day blood pressure reading was documented.

\section{Data analysis}

Collected data was entered in QualityMetric SF-12V2 data quality evaluation software scoring system for calculation of PCS and MCS. Data cleaning, sorting and entry was done into excel worksheet. Descriptive and inferential analyses were done using SPSS version 20 .

\section{Ethical considerations}

Administrative and ethical approval was obtained from the hospitals. Informed consent was obtained from the patients by means of an informed consent form signed by the patients. 


\section{Results}

Socio-demographics of patients

Socio-demographic characteristics of the respondents are presented in table 1 . This shows that majority of the patients are males, between the ages of 61 - 70, educated and are engaged in other forms of employment which could be that some are retired or full-time housewives.

\begin{tabular}{|l|c|}
\hline \multicolumn{1}{|c|}{ Parameters \{Range\} } & Values N (\%) \\
\hline Gender & $72(58.5)$ \\
\hline Male & $49(40.7)$ \\
\hline Female & \\
\hline Age $\{$ range & $10(8.1)$ \\
\hline Below 40 years & $20(16.3)$ \\
\hline 41 - 50 & $37(30.1)$ \\
\hline 51 - 60 & $38(31.7)$ \\
\hline 61 - 70 & $16(13.8)$ \\
\hline Above 70 years & \\
\hline Level of education & $9(7.3)$ \\
\hline Primary school & $34(27.6)$ \\
\hline Secondary school & $78(63.4)$ \\
\hline Post -secondary school & \\
\hline Occupation & $18(14.6)$ \\
\hline Civil servant & $27(22.0)$ \\
\hline Businessman/woman & $5(4.1)$ \\
\hline Teacher & $14(11.4)$ \\
\hline Trader & $58(47.2)$ \\
\hline Others & \\
\hline
\end{tabular}

Table 1: Socio-demographics of respondents.

\section{Clinical Characteristics of patients}

Going by the JNC 7 classification, about 66 (53.7\%) respondents had normal blood pressure values, 18 (14.6\%) of them were prehypertensive, 21 (17.1\%) had stage1 hypertension and 18 (14.6\%) of them had stage 2 hypertension. Almost half of the respondents, $43.9 \%$ were obese as shown in table 2.1. Majority of respondents therefore were overweight.

Table 2.2 presents the clinical characteristics of the patients for both hospitals, designated as Hospital "L" and Hospital "W". This is an overview of the blood pressure, Body Mass Index and QoL of the patients in both hospitals. Result shows that the mean blood pressure of the patients in both health facilities were below 140/90

\begin{tabular}{|l|c|}
\hline \multicolumn{1}{|c|}{ Parameter } & Values N (\%) \\
\hline Systolic blood pressure & \\
\hline Normal & $26(21.1)$ \\
\hline Pre hypertension & $34(27.6)$ \\
\hline Stage 1 hypertension & $43(35.0)$ \\
\hline Stage 2 hypertension & $20(16.3)$ \\
\hline Diastolic blood pressure & \\
\hline Normal & $66(53.7)$ \\
\hline Prehypertension & $18(14.6)$ \\
\hline Stage 1 hypertension & $21(17.1)$ \\
\hline Stage 2 hypertension & $18(14.6)$ \\
\hline Body mass index & \\
\hline Underweight & $1(0.8)$ \\
\hline Normal & $32(26.0)$ \\
\hline Overweight & $36(29.3)$ \\
\hline Obese & $54(43.9)$ \\
\hline
\end{tabular}

Table 2.1: Clinical characteristics.

\begin{tabular}{|l|c|c|}
\hline \multicolumn{1}{|c|}{ Characteristics } & Hospital “L” & Hospital “W” \\
\hline Blood pressure & & Mean (SD) \\
\hline Systolic & $137.2( \pm 20.63)$ & $\begin{array}{c}139.90( \pm \\
18.19)\end{array}$ \\
\hline Diastolic & $85.71( \pm 11.32)$ & $78.49( \pm 12.14)$ \\
\hline Body mass index & & \\
\hline & $29.52( \pm 6.39)$ & $28.92( \pm 5.57)$ \\
\hline Quality of life & & \\
\hline $\begin{array}{l}\text { Mental component } \\
\text { summary }\end{array}$ & & \\
\hline Mean (SD) & $45.98( \pm 8.77)$ & $48.87( \pm 8.73)$ \\
\hline Median & 44.78 & 47.23 \\
\hline Physical component & & \\
\hline Mean (SD) & $47.37( \pm 7.61)$ & $47.01( \pm 7.94)$ \\
\hline Median & 48.79 & 46.08 \\
\hline
\end{tabular}

Table 2.2: Clinical characteristics and quality of life of patients.

mmHg - pre-hypertension, according to the JNC 7 classification. Mean BMI shows that the patients in both hospitals can be classified as overweight. Quality of life Score of patients in both hospitals are below the norm, 50 . 


\section{Predictors of quality of life}

In order to assess predictors of Quality of Life, with respect to the clinical characteristics of the patients, a regression analysis was done and the beta-values obtained. Table 3 shows the regression analysis with the QoL score being the dependent variable and blood pressure the independent variable. An Association was also analyzed between PCS\&MCS with patient demographics. The regression analysis value (Beta coefficients) helps to assess whether predictor variables account for variability in an independent variable.

Using the MCS as the independent variable, systolic blood pressure gave a Beta value of -0.086 , diastolic gave -0.075 , and age of respondents gave 0.061 as the Beta value. Using the PCS as the dependent variable, systolic blood pressure is -0.088 , diastolic is 0.072 , and age of respondents gave -0.048 as Beta coefficient. None of the values was $<0.05$ as a statistically significant value showing that none of them could predict the quality of life of the respondents. Table 3.1-3.3 shows the stated result.

\begin{tabular}{|l|c|c|}
\hline \multicolumn{1}{|c|}{ Model } & $\begin{array}{c}\text { Beta } \\
\text { value }\end{array}$ & $\begin{array}{c}\text { 95\% confidence } \\
\text { interval }\end{array}$ \\
\hline MCS as dependent variable & & \\
\hline Systolic blood pressure & -0.086 & $-0.148-(-0.122)$ \\
\hline Diastolic blood pressure & -0.075 & $-0.235-(-0.131$ \\
\hline Body mass index & 0.093 & $-0.136-(0.060)$ \\
\hline PCS as dependent variable & & \\
\hline Systolic blood pressure & -0.088 & $-0.130-(-0.027)$ \\
\hline Diastolic blood pressure & 0.072 & $-0.113-0.051$ \\
\hline Body mass index & 0.121 & $-0.83-0.129$ \\
\hline
\end{tabular}

Table 3.1: Relationship between clinical characteristics and quality of life score as dependent variable.

\section{Correlates of Quality of life}

Table 4 shows a correlation matrix between the variables and quality of life components. A statistically significant positive correlation was seen between diastolic and systolic blood pressure ( $p=0.000$ ) as well as diastolic blood pressure and Body Mass in$\operatorname{dex}(p=.022)$. This implies that there is a corresponding increase in systolic blood pressure as diastolic blood pressure increases., and a corresponding increase in diastolic blood pressure, as BMI increases. However, this model did not show any statistically significant correlation between Quality of Life and other variables.

\begin{tabular}{|l|c|c|c|l|l|l|}
\hline Variables & Number & $\begin{array}{c}\text { Mean } \\
\text { score }\end{array}$ & $\begin{array}{c}\text { Standard } \\
\text { error }\end{array}$ & t-value & p-value & $\begin{array}{c}\text { 95\% Cl } \\
\text { [range\} }\end{array}$ \\
\hline Gender & & & & & & \\
\hline Male & 72 & 48.6793 & 7.27709 & & & \\
\hline Female & 49 & 45.6120 & 8.20660 & & & \\
\hline $\begin{array}{l}\text { Age } \\
\text { \{range }\end{array}$ & & & & & & \\
\hline $\begin{array}{l}\text { Below } 40 \\
\text { years }\end{array}$ & 10 & 50.3020 & 7.37292 & & & \\
\hline $41-50$ & 20 & 47.6285 & 5.77040 & & & \\
\hline $51-60$ & 37 & 47.9905 & 9.33149 & -0.488 & 0.626 & 0.087 \\
\hline $61-70$ & 38 & 44.1139 & 7.34014 & & & \\
\hline $\begin{array}{l}\text { Above } 70 \\
\text { years }\end{array}$ & 16 & 50.1863 & 4.62685 & & & \\
\hline
\end{tabular}

Table 3.2: Association of patient demographics with PCS mean score.

\begin{tabular}{|l|c|c|c|l|l|l|}
\hline Variables & Number & $\begin{array}{c}\text { Mean } \\
\text { score }\end{array}$ & $\begin{array}{c}\text { Standard } \\
\text { error }\end{array}$ & T value & p-value & $\begin{array}{c}\text { 95\% cl } \\
\text { [range }\end{array}$ \\
\hline Gender & & & & & & \\
\hline Male & 72 & 48.6793 & 8.46382 & & & \\
\hline Female & 49 & 45.4859 & 9.10653 & & & \\
\hline $\begin{array}{l}\text { Age } \\
\text { \{range\} }\end{array}$ & & & & & & \\
\hline $\begin{array}{l}\text { Below } 40 \\
\text { years }\end{array}$ & 10 & 45.5280 & 8.51172 & & & \\
\hline \begin{tabular}{l}
$41-50$ \\
\hline
\end{tabular} & 20 & 42.8665 & 8.96382 & 0.613 & 0.541 & $-0.102-$ \\
\hline $51-60$ & 37 & 49.7324 & 8.68062 & & & 0.068 \\
\hline $61-70$ & 38 & 48.6918 & 8.56724 & & & \\
\hline $\begin{array}{l}\text { Above } 70 \\
\text { years }\end{array}$ & 16 & 45.6700 & 8.15806 & & & \\
\hline
\end{tabular}

Table 3.3: Association of patient's demographics with MCS mean score.

\section{Discussion}

The mean score for PCS was 47.19 and that for MCS was 47.38 in this study. The physical domain was found to be more affected than the mental domain. Also, $43.9 \%$ of the total respondents were obese which accounted for the majority of them. Using the SF-36 survey, various studies have reported reduced physical HRQoL scores among obese individuals compared with non-obese patients, 


\begin{tabular}{|c|c|c|c|c|c|c|c|c|}
\hline & & 1 & 2 & 3 & 4 & 5 & 6 & 7 \\
\hline 1 & $\begin{array}{l}\text { Age of respon- } \\
\text { dents }\end{array}$ & & & & & & & \\
\hline 2 & Gender & $-.311^{* *}$ & & & & & & \\
\hline 3 & $\begin{array}{l}\text { Systolic blood } \\
\text { pressure }\end{array}$ & 0.004 & $-.020 * *$ & & & & & \\
\hline 4 & $\begin{array}{c}\text { Diastolic blood } \\
\text { pressure }\end{array}$ & $-.273^{* *}$ & 0.059 & $.629 * *$ & & & & \\
\hline 5 & $\begin{array}{c}\text { Physical Compo- } \\
\text { nent Summary } \\
\text { of QoL }\end{array}$ & -.087 & -.169 & -.027 & .051 & & & \\
\hline 6 & $\begin{array}{l}\text { Mental Compo- } \\
\text { nent Summary } \\
\text { of QoL }\end{array}$ & .068 & -.178 & -.122 & -.131 & .122 & & \\
\hline 7 & Body Mass Index & -.105 & $.242^{* *}$ & .144 & $.208^{*}$ & .108 & -.043 & \\
\hline
\end{tabular}

Table 4: Pearson's correlation matrix between the variables.

$$
\begin{aligned}
& * \text { Significant at } 0.05 \text { level }(2-\text { tailed }) \text {. } \\
& { }^{* *} \text { Significant at } 0.01 \text { level }(2-\text { tailed }) \text {. }
\end{aligned}
$$

but insignificant or no differences on mental HRQoL [9-12]. Thus, obesity might explain the low scores of the physical component.

The average mental component score was 47.38 , which were below the norm (50). Vitality is a component of mental health and if this is affected, low mental component summary can result. This agrees with the results of the study conducted in India by Gusmao., et al. [13] and Silqueira., et al. [14], which found lower QoL scores in the vitality domain. Low scores in vitality also tells that the patient have decreased energy. Though hypertension is seen as an asymptomatic condition, increasing symptom count and BP is a major determinant of the QOL of hypertensive [15].

Gender, marital status, occupation of the respondents was not predictors of the quality of life and had no effect on the PCS and MCS. These values therefore were insignificant as indicators of health-related quality of life; this conflicts with the study done in Iraq that showed gender, age, marital status and occupation were the main indicators of HRQoL, and female patients, the elderly, those without spouses and did not have jobs or retired were significantly negatively associated with quality of life [16]. The Beta value shows that none of the factors such as blood pressure, body mass index or age of respondents alone can fully predict any of the quality of life components (PCS and MCS). Although gender was not a predictor of the quality of life in both physical and mental component, it was seen that quality of life was higher in males $(48.67 \%)$ than in females $(45.48 \%)$ which contradicts another study [17] where the reverse was the case. This study also showed that the level of education is not a predictor of quality of life. This is in contrast with the research done in Nepal which revealed education as a predictor of quality of life as higher education results in better understanding of the disease state and better adherence [18-21]. Low quality of life is seen in this research especially among the modal population - about $31.7 \%$ of the respondents were between the ages of 61-70 years and this accounted for the majority in the total population- and this is in line with studies conducted by Bardage., et al. [22] and Wang., et al. [23], which showed similar findings where they concluded that hypertension was more prevalent among elder population and reduced their quality of life. It may be due to influences of environmental factors and the effect of genetically programmed senescence in the body systems [24]. During the aging process, health hazards may arise as a result of physiological and functional changes, making the individual more vulnerable to chronic diseases.

\section{Limitation of the Study}

Limitation of this study includes the fact that this study was a descriptive cross-sectional study which enables us to explore some associations and predictors of QoL of hypertensive patients but predictors such as the economic status of respondents and the type of antihypertensive medicines were not taken into consideration in this study which might be one of the important predictors of QoL. Patients with co-morbidities were not excluded from the study so this might also have affected their quality of life such that hypertension alone might not have defined their QoL.

\section{Conclusion}

Despite conscious efforts to improve blood pressure in the health of the hypertensive patients encountered in this study, poor quality of life persisted which is shown by MCS and PCS scores below the norm of 50 in both health facilities.

There was no association between Quality of life and patient demographics in hypertensive patients, although other studies reported association. 


\section{Bibliography}

1. Reddy KS. "Hypertension control in developing countries; generic issues". The Journal of Clinical Hypertension 10.1 (1996): 33-38.

2. Ferrans CE. "Definitions and conceptual models of quality of life". In: Lipscomb J, Gotay CC, Snder C, editors, outcomes assessment in cancer. Cambridge, England: Cambridge university (2005): 14-30.

3. Higginson IJ and Carr AJ. "How can quality of life measures be used in clinical settings?" British Medical Journal 322 (2001): 1297-1300.

4. Ezzati M., et al. "The comparative risk assessment collaborating group selected major risk factor and regional burden of disease". Lancet 360 (2002): 1347-1360.

5. Oparah AC. "Essentials of pharmaceutical care" 5 (2010): 202.

6. Wang R., et al. "Impact of hypertension on health related quality of life population based study in Shanghai, China". Public Health 123 (2009): 534-539.

7. Ware JE., et al. "SF-36 physical and mental health summary scales; a user manual". Boston: The health institute (1994).

8. Medical Outcome Trust (2006).

9. Mena-Martin FJ., et al. "Health-related quality of life of subjects with known and unknown hypertension: results from the population based Hortega study". Journal of Hypertension 21 (2003): 1283-1289.

10. Wiczinski E., et al. "Obesity and health-related quality of life: does social support moderate existing associations?" British Journal of Health Psychology 14 (2009): 717-734.

11. Renzaho A., et al. "Associations between body mass index and health-related quality of life among Australian adults". Quality of Life Research 19.4 (2010): 515-520.

12. Huang IC., et al. "The relationship of excess body weight and health related quality of life: evidence from a population study in Taiwan". International Journal of Obesity 30 (2006): 12501259.

13. Gusmao JL., et al. "Health-related quality of life and blood pressure control in hypertensive patients with and without complications". Clinical Science 64.7 (2009): 619-612.

14. Sivalal S. "Health technology assessment in the Asia Pacific region". International Journal of Technology Assessment in Health Care 25.1 (2009):196-201.

15. Erickson SR., et al. "Relationship Between Symptoms and Health-Related Quality of Life in Patients Treated for Hypertension". Pharmacotherapy 24 (2004): 344-350.
16. Upali WJ., et al. "Gender difference in health- related quality of life of Australian chronically-ill adults: patient and physician characteristics do matter". Health and Quality of Life Outcomes 11 (2013): 102.

17. Al- Mandhari., et al. "Assessment of perceived health status in hypertensive and diabetes mellitus patients at primary health centers in Oman". International Journal of Preventive Medicine 2.4 (2011): 256-263.

18. Bardage C and Isacson DGL. "Hypertension and health-related quality of life: an epidemiological study in Sweden”. Journal of Clinical Epidemiology 54 (2001): 172-181.

19. Youssef RM., et al. "Factors affecting the quality of life of hypertensive patients". Eastern Mediterranean Health Journal 11 (2005): 109-118.

20. Zygmuntowicz M., et al. "Comorbidities and quality of life in hypertensive patients". Polish Archives of Internal MedicinePolskie 122.7-8 (2012): 333-340.

21. Al-Mandhari A., et al. "Assessment of perceived health status in hypertensive and diabetes mellitus patients at primary health centers in Oman". International Journal of Preventive Medicine 2.4 (2011): 256-263.

22. Bardage C., et al. "A swedish population-based study on the relationship between the SF-36 and health utilities to measure health in hypertension". Blood Pressure 12 (2003): 203-210.

23. Ware JE Jr., et al. "Comparison of methods for the scoring and statistical analysis of SF-36 health profile and summary measures: summary of results from the Medical Outcomes Study". Medicine Care 33.4-1 (1995): AS264-AS279.

24. Kokiwar PR., et al. "Prevalence of hypertension in a rural community of central India". The Journal of the Association of Physicians of India 60 (2012): 26-29.

\section{Assets from publication with us}

- Prompt Acknowledgement after receiving the article

- Thorough Double blinded peer review

- Rapid Publication

- Issue of Publication Certificate

- High visibility of your Published work

Website: www.actascientific.com/

Submit Article: www.actascientific.com/submission.php Email us: editor@actascientific.com

Contact us: +919182824667 